\title{
A história falsificada: nacionalismos e revisionismos históricos na Argentina
}

\author{
Falsified history: nationalism and historical revisionism in Argentina
}

GOEBEL, Michael. La Argentina partida: nacionalismos y políticas de la historia. Buenos Aires: Prometeo Libros, 2013. 328 p.

\section{Thiago Henrique Oliveira Prates}

thoprates@gmail.com

Doutorando em História

Universidade Federal de Minas Gerais

Rua Bento Mendes Castanheira, 40, apto. 505, Dona Clara

31260-270 - Belo Horizonte - Minas Gerais

Brasil

Palavras-chave

Historiografia argentina, Nacionalismo; Argentina.

Keywords

Argentine historiography; Nationalism; Argentina. 
Os numerosos episódios de xenofobia, racismo, intolerância religiosa e recusa aos processos de globalização ocorridos na última década têm levado a intelectualidade a refletir sobre um fenômeno próprio da modernidade: o nacionalismo. Comumente associado às direitas, embora não restrito a elas, este tema amplamente estudado e teorizado retorna às ciências sociais em um momento de suposta crise da sociedade liberal e de debates sobre as identidades nacionais, a tradição e os passados coletivos.

Embora o crescimento dos nacionalismos contemporâneos seja mais expressivo na Europa e nos Estados Unidos, a sua presença na América Latina também pode ser notada. Na região, a expressão atual do fenômeno já possuiu natureza distinta e precedeu a ascensão dos grupos de extrema-direita que hoje, progressivamente, ganham mais espaço. Herdeiras dos discursos nacionaispopulares dos anos 1960, as esquerdas reformistas e progressistas das décadas de 1990-2000 que chegaram ao poder - a chamada onda rosa - se valeram da retórica nacionalista e anti-imperialista para se oporem ao neoliberalismo e fundamentar os seus projetos de poder: Hugo Chávez, Néstor Kirchner, Evo Morales e Rafael Correa mobilizaram o passado nacional, seus símbolos e as representações do povo para se contrapor ao Fundo Monetário Internacional e ao Consenso de Washington, ao passo que legitimavam suas políticas redistributivas e nacionalizantes. Em períodos mais recentes, Nicolás Maduro recorreu e recorre ao discurso nacionalista para legitimar o seu contestado governo, ao passo que Cristina Kirchner mobilizou mais de 8 mil argentinos no Stadium Luna Park, em Buenos Aires, no dia 12 de agosto de 2014, sob a consigna Patria o Buitres (Pátria ou Abutres) contra o fundo monetário Elliott Associates.

Nesse sentido, ao observarmos a importância histórica que os nacionalismos tiveram na política latino-americana, vale a pena se debruçar em obras recentes que abordam a temática, como a do alemão Michael Goebel, La Argentina partida: nacionalismos y políticas de la historia, impressa na Argentina em 2013 pela editora Prometeo, resultado de sua pesquisa de doutorado na University College London, bem como uma tradução e atualização de sua versão inglesa publicada em 2011. Dividido em cinco capítulos, La Argentina partida é um livro construído por meio de uma narrativa que segue uma ordem cronológica: parte da constituição do Estado Nacional argentino e chega até os recentes governos de Cristina Kirchner, analisando os nacionalismos, as escritas da história e as narrativas de passado em diferentes momentos do processo histórico do país.

A priori, o livro de Goebel trata de um assunto vastamente trabalhado, o nacionalismo argentino no século XX. As discussões incorporam todos os textos clássicos sobre o nacionalismo, de Ernest Renan a Benedict Anderson, Eric Hobsbawm e Ernest Gellner. Da mesma maneira, seu livro traz os principais aportes argentinos ao estudo do nacionalismo vernáculo, sobretudo em sua vertente de extrema-direita, como aqueles feitos por Fernando Devoto, Federico Finchelstein, Marysa Navarro Gerassi, Enrique Zuleta Álvarez e Cristian Buchrucker, além de uma bibliografia em língua inglesa, a saber, Alberto Spektorowski e David Rock. Igualmente, a sua análise sobre o peronismo incorpora os clássicos, de Carlos Altamirano a Mariano Plotkin, Daniel James e Richard Gillespie. 
Entretanto, seu estudo sobre um tema tão discutido ganha contornos inovadores devido ao recorte temporal de média duração, todo o século $X X$, que permite ao autor efetuar comparações sobre as várias vertentes do nacionalismo argentino, desde sua versão elitista, xenófoba e mesmo fascista, iniciada na década de 1930, ao nacionalismo popular e revolucionário que teve sua gestação após a queda de Perón em 1955, logo radicalizado e com forte inspiração marxista. Goebel consegue estabelecer semelhanças entre ambos: o seu caráter antiliberal e muitas vezes autoritário; os símbolos compartilhados; a figura de um líder comum (Perón); certo anti-intelectualismo e antiacademicismo; a valorização da cultura vernácula e a busca por raízes nacionais; os usos de estratégias discursivas pautadas em maniqueísmos e dicotomias irreconciliáveis (nacional $x$ estrangeiro, pátria $x$ imperialismo, povo $x$ oligarquia, liberalismo $x$ nacionalismo); um inimigo comum (a oligarquia liberal alinhada com os interesses estrangeiros ou os vende-pátria); a defesa de um Estado interventor e de uma política econômica protecionista; o recurso à violência e a intolerância política; algumas trajetórias individuais que se cruzavam, sobretudo em organizações radicais de finais da década de 1950 e início da de 1960, como a Tacuara; a defesa da causa argentina no conflito das Malvinas em 1982.

A perspectiva adotada também permite delinear as diferenças entre dois projetos políticos com objetivos distintos, um voltado para a manutenção da ordem e o outro para a transformação radical da sociedade: a valorização das raízes hispânicas, da tradição ibérica, do catolicismo e da descendência étnica espanhola por parte das direitas, algo praticamente inexistente nas esquerdas, que ainda buscaram recuperar, mesmo que de forma tímida, o elemento indígena na sociedade argentina; a valorização da cultura popular - como o tango, a milonga e o lunfardo - por parte do nacionalismo de esquerda; a presença de uma forte xenofobia e antissemitismo na direita nacionalista, igualmente inexistente em esquerdas internacionalistas e afinadas com o latinoamericanismo revolucionário e com o terceiro-mundismo propagado sobretudo por Cuba; a defesa da causa territorial por parte das direitas, que quase levou a um conflito armado com o Chile em 1978. Além disso, o historiador mostra como essas duas vertentes do nacionalismo disputaram a hegemonia dentro do movimento peronista e entraram em conflito armado ao longo da década de 1970 por meio das guerrilhas de esquerda, capitaneadas sobretudo pelos Montoneros dentro do peronismo revolucionário, e o terrorismo paramilitar da extrema-direita, conduzido principalmente pela Aliança Anticomunista Argentina, a chamada Triple A, liderada pelo também peronista José López Rega.

Se a análise de fôlego sobre os nacionalismos argentinos já valem a leitura de La Argentina partida, o autor inova ainda ao estudar a interação dos nacionalismos com o que chama de política da história, termo popularizado na Argentina pelo ensaísta Arturo Jauretche (JAURETCHE 1959) e que Goebel (2013, p. 11) define como as "formas por meio das quais se escreve e se mobiliza a história com o objetivo de afetar a distribuição do poder político em uma sociedade". Buscando compreender a construção discursiva e simbólica do nacionalismo, o historiador estabelece como foco as maneiras como intelectuais 
e políticos produziram e utilizaram interpretações da identidade nacional fomentando, cooptando ou reprimindo narrativas históricas.

Ao fazê-lo, Goebel se envereda pelos escritos fundacionais do Estado liberal argentino e por algumas correntes historiográficas desse país, como o mitrismo, forma em que os oponentes do liberalismo chamaram as práticas e escritos políticos de Bartolomé Mitre; a Nueva Escuela Histórica, responsável pela profissionalização e institucionalização da atividade do historiador; e o revisionismo histórico, ligado às extremas-direitas dos anos 1930-1940, e o revisionismo de esquerda, surgido após a queda de Perón em 1955, ambos profundamente antiliberais, críticos da academia e questionadores das vertentes historiográficas hegemônicas. A bibliografia utilizada traz os principais nomes dos estudos sobre historiografia argentina, bem como os dos autores e autoras que trataram do revisionismo, tema que ainda precisa ser mais estudado, a saber, Alejandro Cattaruzza, Diana Quattrocchi-Woisson, Fernando Devoto, Nora Pagano, Maristella Svampa, Alejandro Eujanian, Julio Stortini e Tulio Halperín Donghi, além das memórias dos próprios revisionistas. No campo da história intelectual do período abordado, o autor se vale dos clássicos como Oscar Terán, Beatriz Sarlo, Carlos Altamirano e Silvia Sigal.

Após comentar rapidamente sobre sistematização e institucionalização da disciplina histórica na Argentina, o historiador alemão observa que intelectuais autoritários de extrema-direita e outros ligados a vertentes populistas fundaram o chamado revisionismo no período de profunda crise política e institucional de

166 finais da década de 1920 que culminou com o golpe militar do general Uriburu e a queda do presidente radical Hipólito Yrigoyen em 1930, a crise econômica de 1929, as transformações sociais propiciadas pela imigração massiva e pela expansão da participação política, tudo acompanhado de uma profunda descrença no Estado liberal argentino. O revisionismo dessa década de 1930 se fundamentou no ataque à historiografia chamada liberal e às concepções liberais de nação, acusadas de adotarem referentes estrangeiros, antinacionais e ligados aos interesses imperialistas, e de não representarem, portanto, o verdadeiro "ser nacional". Ligada a isso, está a ideia, amplamente popularizada por Ernesto Palacio (1939), de uma história falsificada por uma elite intelectual liberal que não defendia os interesses nacionais e que teria construído deliberadamente uma narrativa sobre o passado com o intuito de legitimar um projeto político oligárquico e alienador da identidade argentina.

Como contraproposta, os revisionistas buscaram inverter os parâmetros de análise da historiografia que taxavam como liberal: criticavam Mitre e Sarmiento por imporem uma ideologia avessa à índole argentina, criticavam o centralismo de Buenos Aires, valorizavam os caudilhos do interior como próceres nacionais, homens como Facundo Quiroga, "El Chacho" Peñaloza e Manuel Dorrego e, sobretudo, resgataram a figura de Juan Manuel de Rosas. Exaltavam os valores viris, católicos e hispânicos de caudilhos que, a seu ver, defenderam a integridade da nação frente ao jugo estrangeiro. Com isso, criaram o mito das duas Argentinas, uma Buenos Aires cosmopolita, corrompida pela cultura estrangeira, e um interior imaculado, fonte de uma nação original e pujante. 
Fundaram o Instituto de Investigaciones Históricas Juan Manuel de Rosas como contraponto da Academia Nacional de Historia (anteriormente Junta Historia y Numismática Americana), e homens como Ernesto Palacio, Ramon Doll, Carlos Ibarguren, Manuel Gálvez, José María Rosa (que posteriormente aderiu a posições mais progressistas) e os irmãos Julio e Rodolfo Irazusta escreveram livros, com enfoque em Rosas, sobre os grandes homens do século XIX, que deveriam servir como lastro da argentinidade, verdadeiros heróis nacionais que se opuseram aos traidores Sarmiento, Mitre e Roca. Em termos das temporalidades existentes nessas narrativas, era possível perceber uma conexão intencional entre passado e presente: a narrativa dos tempos idos serviria para explicar o momento em que se vivia e legitimar práticas políticas autoritárias.

A partir da ascensão do peronismo, os revisionistas mantiveram uma relação dúbia com o governo. Por um lado, alguns de seus membros conseguiram cargos de ínfima importância e, por outro, parte de seu discurso foi apropriado e diluído na retórica peronista: uns apoiaram o governo que surgia e se firmava, e outros, como os Irazusta, opuseram-se. Entretanto, a queda de Perón em 1955 alteraria profundamente o revisionismo: a sua derrocada pela autoproclamada Revolução Libertadora deu início a um movimento intelectual que buscava compreender o fenômeno que o país havia experimentado entre 1945 e 1955 e que se recusava a desaparecer após a destituição de seu líder.

A intelectualidade argentina se debruçou sobre o peronismo para melhor entender o seu país, e a nova geração de revisionistas integrou essa corrente. De fato, seus antecedentes vinham dos nacionalismos populistas anteriores, como a Fuerza de Orientación Radical de la Joven Argentina (FORJA) de Scalabrini Ortiz, John William Cooke e Arturo Jauretche, mas os revisionistas que ganhavam espaço eram os fundadores da chamada esquerda nacional, a esquerda marxista e revolucionária de fins dos anos 1950 e princípio dos anos 1960 que se convertia ao peronismo e ao nacionalismo, representada por homens como o trotskista Jorge Abelardo Ramos, os comunistas Rodolfo Puiggrós, Jorge Spilimbergo e Eduardo Astesano e o radical Juan José Hernández Arregui. Esse revisionismo se assemelhava ao anterior ao criticar o establishment liberal e perceber na chamada oligarquia ligada ao imperialismo a origem dos males do país. Entretanto, apesar de endossarem um discurso maniqueísta semelhante, abandonaram as concepções elitistas e buscaram valorizar elementos populares da cultura nacional. Sua concepção de história igualmente possuía um caráter didático, pois a concebiam como um retorno ao passado para tirar lições para o presente; porém, essa visão também engendrava um programa de transformação radical do presente e construção de uma sociedade futura. Os revisionistas de esquerda, como os chama Goebel, viam em Perón não apenas uma continuidade da cultura nacional e popular dos caudilhos do século XIX, um bastião da soberania nacional, mas também a plataforma a partir da qual a revolução socialista se iniciaria. Estes revisionistas foram os responsáveis por iniciar, na Argentina, os debates sobre as possibilidades de conciliação entre nacionalismo e marxismo, numa tentativa de construção do que nomeavam como socialismo nacional. 
Posteriormente, Goebel se debruça sobre a conturbada década de 1970, sobre os conflitos entre os próprios revisionistas de vertentes distintas, os usos políticos da história pelos grupos armados e pelas extremas-direitas que apoiavam o terrorismo paramilitar, as narrativas do passado utilizadas pela Junta que liderou o Processo de Reorganização Nacional (1976-1983) e aquelas dos governos seguintes, de Alfonsín a Menem. Seu objetivo é expor os usos práticos do passado que legitimavam a violência política e descrever o declínio da narrativa revisionista a partir da ditadura instaurada em 1976, revisionismo que experimentou uma pequena retomada em meados da década de 2000 e princípios da de 2010.

Goebel mostra a todo momento as relações entre esses intelectuais ligados aos revisionismos e os mais diversos grupos políticos, seja pela produção e publicações de livros, revistas e jornais, pela ação direta em grupos radicais, como os Montoneros, ou pela atuação como membros do Estado. O autor também trata de como dirigentes políticos se valeram do repertório discursivo revisionista e mobilizaram o seu imaginário. Os revisionistas nunca conseguiram se tornar hegemônicos, institucionalizar-se ao ponto de substituir a historiografia que criticavam, mas foram bem-sucedidos em criar na sensibilidade argentina a ideia de duas nações, de uma história falsificada e de teorias conspirativas que respondiam às perguntas sobre as sucessivas crises que atingiam a Argentina. Para Goebel, o que une os distintos nacionalismos e revisionismos é a crítica ao paradigma de nação liberal e a reinvenção de um passado argentino que legitimaria a nação desejada (GOEBEL 2013, p. 25).

A documentação utilizada para a publicação é bastante variada, o que agrega um caráter inovador à empreitada: livros de importantes intelectuais, revistas e jornais de distintos grupos políticos, boletins de instituições de História, discursos de políticos e estadistas, documentação de instituições culturais e de sindicatos, antecedentes penais de membros de organizações políticas extremistas, filmes e documentários, correspondências diplomáticas do Ministério dos Assuntos Exteriores do Reino Unido e, por fim, entrevistas com alguns dos atores do período estudado.

Entretanto, um trabalho que analisa um período tão vasto, ainda que de maneira cuidadosa, peca por vezes no quesito profundidade, o que faz com que a comparação das distintas vertentes do nacionalismo e dos revisionismos, o ponto mais atrativo e inovador da obra, possa carregar erros. Goebel afirma que os revisionistas eram sobretudo empiristas, que faziam poucas discussões teóricas e se limitavam a elogiar os seus pares. Se, por um lado, isso é pertinente para os revisionistas ligados às extremas-direitas, o mesmo não pode ser dito para a intelectualidade conformada pela esquerda nacional e pelo peronismo revolucionário. O autor por vezes ignora o marxismo como marco teórico ou banaliza as discussões efetuadas pelos marxistas (reconhece uma sólida formação apenas em Rodolfo Puiggrós), bem como deixa de lado todo o peso das teorias da dependência (não há nem sequer uma menção), das leituras de Lenin sobre o imperialismo e a importância da lei do desenvolvimento desigual e combinado de Trotsky na formação da intelectualidade de esquerda, assuntos 
abordados em outros artigos publicados pelo mesmo autor. O trabalho de Omar Acha, Historia crítica de la historiografía argentina. Vol. 1: Las izquierdas en el siglo XX (2009), publicada pela mesma editora Prometeo, contribuiria para a resolução dos problemas apresentados. De qualquer forma, Goebel se restringe a apontar um marco teórico frágil nos revisionismos, mas não se detém sobre o assunto, embora o tenha feito em sua tese.

O historiador parece buscar demasiadas aproximações e acaba por efetuar comparações improváveis: Goebel afirma que o intelectual revolucionário Frantz Fanon seria o correlato de esquerda do integralista católico, monarquista e principal intelectual da Ação Francesa, Charles Maurras, nas referências de leitura dos nacionalistas argentinos da década de 1960 (GOEBEL 2013, p. 141). Além disso, não distingue as violências políticas praticadas pelas esquerdas e direitas nas décadas de 1960 e 1970. Por vezes, Goebel assimila a própria dicotomia entre liberalismo e autoritarismo, equipara nacionalismo a ideais antidemocráticos e não consegue perceber que traços autoritários perpassam grande parte da cultura política argentina ao longo do século XX, seja ela liberal ou não.

Algumas figuras importantes também não receberam a devida atenção de Goebel, embora o escopo de seu trabalho seja louvável. O alemão deixou de lado indivíduos que, embora não se percebessem como revisionistas, contribuíram para o debate, como o trotskista Milcíades Peña e sua revista Fichas, publicada nos anos 1960, e o anarquista Osvaldo Bayer. Da mesma maneira, deixou de lado autores revisionistas importantes para os anos 1970, como Luis Alén Lascano e Norberto Galasso. Este último consta em sua bibliografia, mas não foi dedicada a ele uma análise mais profunda.

Apesar dos problemas apontados, La Argentina partida, de Michael Goebel, certamente se torna uma referência. Esta obra de fôlego, ambiciosa e bem escrita contribui para o estudo do nacionalismo argentino de uma perspectiva de média duração, para a análise das trajetórias de intelectuais ligados aos movimentos nacionalistas, para a compreensão do revisionismo histórico, corrente tão difundida na Argentina, e para a relação entre nacionalismo e narrativas do passado.

\section{Referências bibliográficas}

ACHA, Omar. Historia crítica de la historiografía argentina. Las izquierdas en el siglo xx. Buenos Aires: Prometeo Libros, 2009.

GOEBEL, Michael. La Argentina partida: nacionalismos y políticas de la historia. Buenos Aires: Prometeo Libros, 2013.

A Movement from Right to Left in Argentine Nationalism? The Alianza Libertadora Nacionalista and Tacuara as Stages of Militancy. Bulletin of Latin American Research, v. 26, n. 3, p. 356-377, 2007.

Marxism and the Revision of Argentine History in the 1960s. Estudios Interdisciplinarios de América Latina y el Caribe, v. 17, n. 1, p. 161$184,2006$. 
. Argentina's Partisan Past: nationalism, peronismo and historiography, 1955-1976. Thesis (PhD in History) - Department of History, University College London, London, 2006.

JAURETCHE, Arturo. Politica nacional y revisionismo histórico. Buenos Aires: A. Pena Lillo, 1959.

PALACIO, Ernesto. La historia falsificada. Buenos Aires: Difusión, 1939. 